\title{
EFEITO BENJAMIN BUTTON: A FIGURA DO IDOSO NA REPRESENTAÇÃO DA IDENTIDADE DE MARCAS CONTEMPORÂNEAS.
}

\author{
Benjamin Button Effect: the figure of elderly in the identity representation of \\ contemporary brands.
}

\section{Efecto Benjamin Button: la figura de ancianos en la representación de la identidad de marcas contemporáneas.}

\author{
Flavia Igliori Gonsales ${ }^{1}$ \\ Sandra Souza ${ }^{2}$
}

\begin{abstract}
Resumo
As marcas contemporâneas, além de identificar e diferenciar produtos e serviços, são capazes de estabelecer vínculos afetivos com seus públicos. No aspecto visual, as marcas manifestam sua identidade por meio de diversos elementos expressivos, entre eles o identificador visual nominativo (logotipo) e simbólico (símbolo, cor e grafismo). Neste artigo, foram analisadas quatro marcas populares e com décadas de existência, que utilizam a figura do idoso como elemento simbólico da identidade, figura que passou por sucessivos redesenhos a fim de causar um rejuvenescimento na imagem de marca processo que pode ser denominado como efeito Benjamin Button (efeito BB).
\end{abstract}

Palavras-chave: identidade de marca, símbolo gráfico, redesign, idoso, reju venescimento.

\begin{abstract}
Besides identifying and differentiating goods and services, contemporary brands are able to establish affective links with stakeholders. In the visual realm, brands manifest their identity through a myriad of expressive elements, among them the nominative (logotype) and the symbolic (symbol, color and graphic) visual identifiers. In this article, we examine four popular brands, with decades of existence, that use the figure of an elderly as the symbolic

\footnotetext{
${ }^{1}$ Graduada e Mestre em Arquitetura e Urbanismo pela FAU-USP, especialista em Gestão de Projetos Culturais pelo Celacc (ECA-USP). É professora de gestão de marcas em cursos de pós graduação da BSP Business School São Paulo - email: flagonsales@gmail.com.

${ }^{2}$ Livre-docente em Ciências da Comunicação pela ECA USP onde atua como docente e pesquisadora desde 1981, no curso de Comunicação Social, habilitação Propaganda e Publicidade. Lidera o GEIC, Grupo de Estudos da Imagem em Comunicação, e integra a Comissão de Estudo Especial da ABNT-CEE168 para Símbolos Gráficos. E-mail: smrdsouz@usp.br
} 
Efeito Benjamin Button: a figura do idoso na representação da identidade de marcas contemporâneas.

de Flavia Igliori Gonsales e Sandra Souza

element of identity, which has been through successive redesigns in order to rejuvenate the brand image - a process that can be termed as Benjamin Button effect (BB effect).

Keywords: brand identity, graphic symbol, redesign, elderly, rejuvenation.

\section{Resumen}

Además de identificar y diferenciar productos y servicios, las marcas contemporáneas son capaces de establecer vínculos emocionales con sus públicos. En el aspecto visual, las marcas manifiestan su identidad a través de una miríada de elementos expresivos, incluyendo el identificador visual nominativo (logotipo) y simbólico (símbolo, color y gráfico). En este artículo, se examinan cuatro marcas populares, con décadas de existencia, que utilizan la figura de ancianos como elemento simbólico de la identidad, figura que ha pasado por sucesivos rediseños a fin de rejuvenecer la imagen de la marca - proceso que puede ser denominado como efecto Benjamin Button (efecto BB).

Palabras-clave: identidad de marca, símbolo gráfico, rediseño, ancianos, rejuvenecimiento.

\section{INTRODUÇÃO}

Nos tempos atuais, denominados como pós-modernidade (HARVEY 1992), modernidade tardia (HALL 2000), modernidade líquida (BAUMAN 2001), hipermodernidade (LIPOVETSKY 2004), entre outros termos, os conceitos de novo, belo e jovem afloraram e se estabeleceram como motivação social e, por conseguinte, como atributos desejados pelas marcas. Hoje, mais importante do que exibir a fortuna que se possui, é exibir juventude e beleza (LIPOVETSKY \& ROUX 2005). Paradoxalmente, os avanços da medicina e a urbanização da sociedade ampliaram os limites de expectativa de vida da população mundial, que hoje é composta por 600 milhões de pessoas com mais de 60 anos, o que representa 9\% do total de habitantes, segundo a Organização Mundial de Saúde (OMS 2011). No Brasil, em particular, os dados do IBGE $^{3}$ sobre expectativa de vida ao nascer apontam um incremento de, em média, três meses e 29 dias ao longo de 11 anos (de 2000 a 2011), elevando para 74,08 anos a esperança de vida dos brasileiros. Assim,

\footnotetext{
${ }^{3}$ IBGE. Comunicação Social. Em 2011, a esperança de vida ao nascer era de 74,08 anos. Artigo publicado na Sala de Imprensa em 29 nov. 2012. Disponível em:

<http://www.ibge.gov.br/home/presidencia/noticias/noticia_visualiza.php?id_noticia=2271\&id_pagina=1>

Acesso em: 11 mar. 2013.
} 
Efeito Benjamin Button: a figura do idoso na representação da identidade de marcas contemporâneas.

de Flavia Igliori Gonsales e Sandra Souza

num mundo cada vez mais povoado por idosos, a juventude parece se tornar um luxo, um alvo de desejo ainda mais cobiçado do que sempre foi.

Também, desde o final do século passado, as marcas tornaram-se o centro de interesse das empresas, principalmente devido à necessidade de agregar valor a bens e serviços cada vez mais similares e substituíveis, da economia globalizada. Se, anteriormente, o conceito de marca era restrito a um sinal visual para identificar e diferenciar bens de consumo, hoje existe vasta literatura destacando seus aspectos emocionais, expressivos, cognitivos e simbólicos, assim como analisando a importância desses aspectos para uma bem sucedida gestão de marca, ou branding (GOBÉ 2009, 2010; SEMPRINI 2010; LINDSTROM 2005, 2008; SCHMITT \& SIMONSON 2002).

Como as marcas contemporâneas lidam com a questão do envelhecimento em tempos de exacerbação da juventude? Que marcas utilizam a representação gráfica de um idoso/idosa em suas identificações simbólicas? Essas são as perguntas centrais que este artigo buscou investigar, partindo da premissa que a representação gráfica dos idosos está sofrendo o efeito $B B$, efeito Benjamin Button ${ }^{4}$ de rejuvenescimento progressivo nas comunicações de marketing, à medida que, inversamente, o tempo passa e essas marcas se estabelecem como signos de tradição, qualidade e longevidade no mercado.

Na primeira parte deste artigo, buscamos entender o conceito de identidade de marca e sua concretização por meio de elementos visuais. Na segunda parte, investigamos o conceito de idoso na contemporaneidade e identificamos, para análise, logotipos de marcas brasileiras e internacionais cujo componente simbólico é o desenho de um idoso/idosa. As considerações finais inter-relacionam os dois conceitos - idoso e marca- com a tradição publicitária de promover rostos sempre joviais, felizes e sorridentes como condição persuasiva fundamental.

\section{O CONCEITO DE IDENTIDADE DE MARCA}

Existem diferentes conceitos de Identidade de Marca, porém todos concordam com sua importância no processo de gestão de marcas. Para Kapferer, especialista em branding, a identidade determina "as facetas da singularidade e da relevância de marca" (KAPFERER 2008: 171). Em consonância, Aaker e Joachimsthaler consideram que para

\footnotetext{
${ }^{4}$ Em 2008, a Paramount Pictures lançou o filme The Curious Case of Benjamin Button, baseado em um conto homônimo de Scott Fitzgerald, narrando a vida e o amor [improváveis] de um bebê que nasce velho e com o passar do tempo vai rejuvenescendo sua aparência. Na $81^{\mathrm{a}}$ edição da Academy Awards, o filme dirigido por David Fincher recebeu três estatuetas Oscar.
} 
Efeito Benjamin Button: a figura do idoso na representação da identidade de marcas contemporâneas.

de Flavia Igliori Gonsales e Sandra Souza

se obter uma marca forte é necessário desenvolver uma identidade clara e valiosa, a fim de enfrentar as "forças de mercado que enfatizam produtos não-diferenciados e a competição de preços" (AAKER e JOACHIMSTHALER 2007: 49). Semprini (2010) concebe a identidade das marcas contemporâneas como uma entidade semiótica, cujo processo de enunciação permite à marca passar de um estado abstrato, conceitual (projeto de marca) para um estado concreto, de manifestação, envolvendo os cinco sentidos e a vivência dos receptores. Dessa maneira, as formas, cores e outras formas de linguagem - manifestações significantes - quando organizadas perceptivelmente de modo coerente, distinto e persistente no tempo, resultam na construção de uma estética com forte poder expressivo e capaz de suscitar nos públicos da marca reações como "emoção, surpresa, senão até mesmo encantamento e o sonho" (SEMPRINI 2010:173-174).

Colocada a importância da marca e de seu uso consistente ao longo do tempo para a obtenção não apenas de uma identidade, mas uma identidade valorada e personalizada, serão abordados a seguir os diferentes tipos de expressão marcária, foco de estudo deste artigo.

\subsection{Expressões visuais de Identidade de Marca}

Marcas necessitam serem vistas para serem lembradas. Uma marca necessita da manifestação visível e permanente no espaço e no tempo para ser percebida, uma vez que "o homem é um animal ótico [...]", cuja percepção de mundo e conhecimento se dá predominantemente no visual (COSTA 2011: 25).

Segundo Kapferer (2008: 173), “os mais profundos valores da marca devem ser refletidos em sinais externos de reconhecimento, e que devem ser evidentes à primeiravista". Essas expressões perceptíveis são chamadas pelo autor de fontes de identidade ou DNA da marca: o produto ou serviço em si, o nome da marca, seus símbolos visuais e logotipos, personagens, propaganda e embalagens (KAPFERER 2008:188-189). Para as fontes exclusivamente visuais de identidade (no caso, símbolos visuais e logotipos, personagens e embalagem), são destacadas as funções de simbolizar a marca, auxiliando consumidores e simpatizantes a reconhecê-la nos ambientes de consumo, diferenciando-a de suas concorrentes, creditando-lhe características personalizadas e um estilo próprio de se manifestar que acabam por se consolidar em uma cultura da marca.

Aaker (1998) denomina os elementos que expressam a identidade marcária como indicadores de marca, que seriam o nome, o símbolo e o slogan. O termo símbolo é usado para especificar os indicadores exclusivamente visuais, e pode englobar quase tudo: formas 
Efeito Benjamin Button: a figura do idoso na representação da identidade de marcas contemporâneas.

de Flavia Igliori Gonsales e Sandra Souza

geométricas, embalagens, logotipos, pessoas, cenas e personagens. Para o autor, em tempos de empresas, produtos e serviços similares e de difícil diferenciação, "um símbolo pode ser o elemento central do brand equity ${ }^{5}$, a característica diferencial chave da marca" (AAKER 1998: 207, nota nossa).

As manifestações visuais da identidade são especialmente importantes no atual contexto pós-moderno de desmaterialização dos produtos e serviços, uma vez que o grafismo, o uso da cor e a tipografia representam muitas vezes a única maneira de indicar sobre o que se trata o tal produto ou serviço, realizando a tarefa de "estetizar o invisível" (SEMPRINI 2010: 181). Nesse aspecto, as manifestações visuais ocupam um papel central na proposta do autor, por representar o momento de mediação entre projeto de marca e o destinatário, seus públicos.

\subsection{Logotipo e símbolo: elementos centrais da manifestação visual de marcas}

A importância do logotipo como manifestação da identidade de marca, graças à sua capacidade de síntese visual, carga expressiva e simbólica, é unanime na literatura. Ele é considerado o "elemento básico para uma identidade visual consistente" (ALLEN e SIMMONS 2004: 118), a "taquigrafia visual” da marca (MILETSKY e SMITH,2009:11) e "o mais importante ativo visual de uma companhia, assim como o catalizador para os bons e maus sentimentos" que se pode ter sobre ela (GOBÉ 2009: 126).

Originalmente e para puristas, o termo logotipo designa os signos visuais de marca exclusivamente tipográficos, enquanto o termo símbolo designa o [eventual] elemento icônico. Lencastre e Côrte-Real (2010: 7) especificam três componentes do logotipo: o lettering (componente tipográfico), o drawing (componente simbólico, desenhado) e o coloring (código cromático do logotipo). Para eles, o termo logotipo é utilizado tanto em referência às assinaturas visuais exclusivamente tipográficas, como para assinaturas que possuem o elemento simbólico (drawing).

Neste artigo, seguindo a tradição dos primeiros escritórios de design instalados no país e primeiros cursos especializados, utilizaremos logotipo para designar a maneira específica de grafar a parte pronunciável da marca e símbolo, bem como as expressões equivalentes, elemento simbólico e símbolo gráfico para designar a parte icônica, desenhada das marcas, reservando o termo marca para a designação geral do conjunto de

\footnotetext{
${ }^{5}$ Em português, brand equity é traduzido como valor ou patrimônio de marca, embora em muitas traduções o termo técnico original, em inglês, é mantido.
} 
Efeito Benjamin Button: a figura do idoso na representação da identidade de marcas contemporâneas.

de Flavia Igliori Gonsales e Sandra Souza

valores e sentidos associados a todos os identificadores que diferenciem e personalizem um bem colocado no mercado por um fornecedor, bem como à cultura da organização construída a partir desses mesmos identificadores.

Com esta mesma visão polarizada entre palavra e imagem, Chaves (2012) reconhece seis grandes grupos de identificadores marcários em seu esforço de classificar tipologicamente as marcas gráficas, conforme mostra a figura 1 :

Fig. 1 - Esquema de megatipos de marcas gráficas (CHAVES 2012).

Fonte - Pensamento tipológico

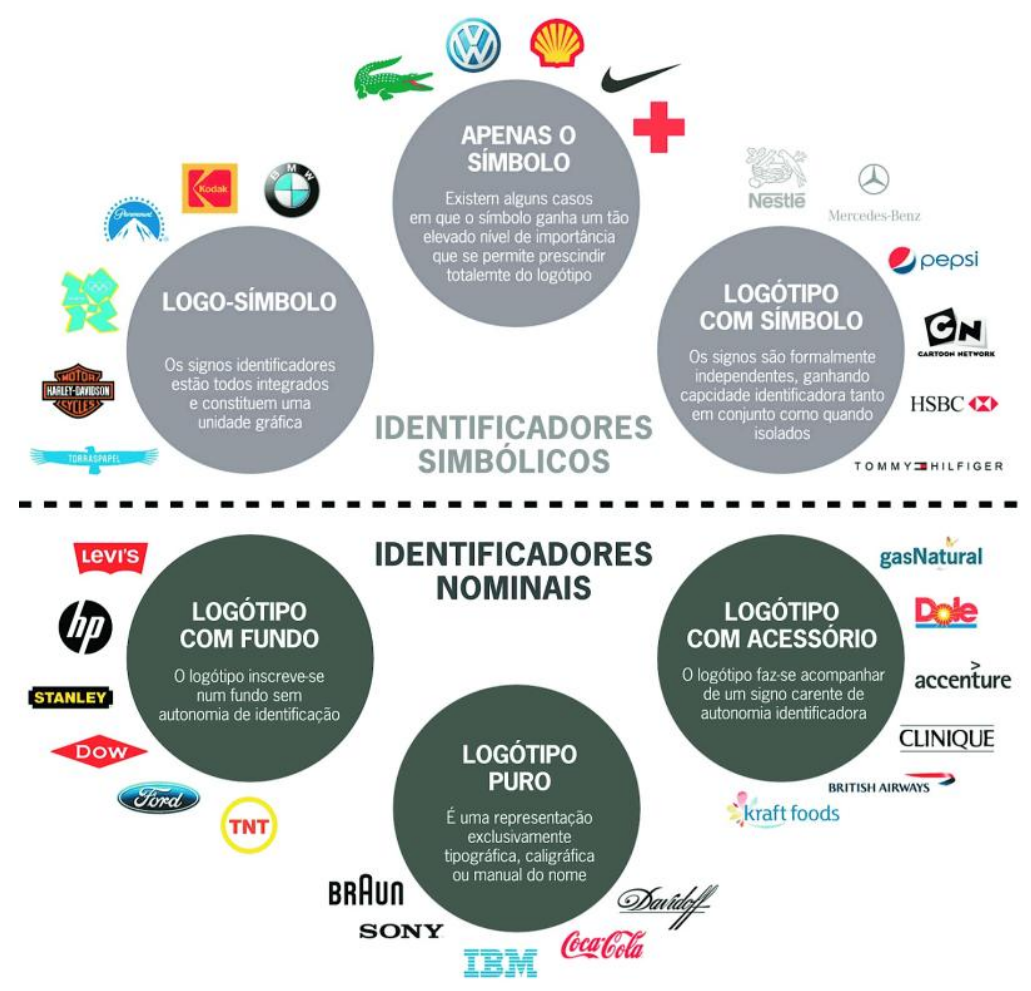

Pode-se ver que a principal diferenciação na classificação de Chaves (2012) se dá entre os identificadores simbólicos (logo-símbolo; símbolo e logotipo com símbolo) e os nominais (logotipo com fundo; logotipo puro e logotipo com acessório).

Uma vez que o corpus de análise são as marcas que utilizam o símbolo do idoso na composição de seu logotipo, o presente artigo abordará os identificadores simbólicos, sejam do tipo logo-símbolo (quando os elementos tipográfico e simbólico estão formal e indissociavelmente integrados em uma unidade gráfica), apenas o símbolo (raros casos onde o símbolo consegue prescindir do elemento tipográfico), e logotipo com símbolo 
Efeito Benjamin Button: a figura do idoso na representação da identidade de marcas contemporâneas.

de Flavia Igliori Gonsales e Sandra Souza

(quando os elementos tipográfico e simbólico são utilizados em espaços contíguos, mas conservam, individualmente, a capacidade de identificar o bem, produto ou serviço).

\section{A REPRESENTAÇÃO DO IDOSO NAS MARCAS CONTEMPORÂNEAS}

Concomitantemente com o início da ascensão das marcas - especificamente a partir de 1980 (SEMPRINI 2010) - o corpo passou a ser um verdadeiro protagonista da cena social e do consumo, devido à imposição do corpo saudável que o envelhecimento demográfico acabou por impor. A atenção ao corpo - que deve estar sempre em forma, hidratado, protegido, alimentado, graças às massagens, prática de esportes, dieta controlada - pode também ser entendida como consequência do enfoque sobre o individualismo, tão discutido e analisado pelos teóricos da pós-modernidade: "a difusão maciça de uma cultura psicológica de massa popularizou as noções de desejo e de prazer e legitimou a construção de projetos individuais, a busca da felicidade privada" (SEMPRINI 2010: 58).

A luta contra o envelhecimento e o excesso de peso não é exclusiva das camadas mais abonadas da sociedade, está em todos os grupos, devido ao crescimento do consumo, do lazer e do bem-estar, fazendo do supérfluo (ou seja, do não estritamente necessário para a sobrevivência) uma "aspiração de massa legítima" (LIPOVETSKY e ROUX 2005: 57).

Se os consumidores contemporâneos buscam estar sempre jovens e saudáveis, podese falar o mesmo das marcas que eles estão ávidos por comprar, numa transposição do imperativo da juventude para o âmbito do branding. Kapferer comenta que as expressões frequentemente utilizadas para se falar da idade das marcas são idênticas aos termos usados para se falar de uma pessoa: "a marca está envelhecendo", "está mostrando sinais de idade" (KAPFERER 2008: 443). Para o autor, quando a marca parece não pertencer mais ao seu tempo e quando perde sua energia intrínseca, ela passa a impressão de ser velha, o que pode ser sentido pelos seus diversos públicos: clientes, fornecedores, distribuidores, funcionários e mesmo os não clientes, que a comparam com os principais concorrentes.

Ainda segundo o autor, o conceito de envelhecimento da marca pode vir de dois diferentes fatores-causa: 1) o declínio da importância ou relevância da marca, que não se diferencia, impacta ou inova tanto quanto outrora, o que pode levar à repetição e até mesmo ao tédio; 2) o reflexo da imagem do consumidor típico ser alguém velho e, mesmo para uma marca voltada para o público maduro, "nunca é aconselhável a imagem de marca ser muito associada a uma clientela idosa" (KAPFERER 2008: 444). De um modo ou de outro, pode-se perceber a importância das marcas saberem permanecer no tempo sem 
Efeito Benjamin Button: a figura do idoso na representação da identidade de marcas contemporâneas.

de Flavia Igliori Gonsales e Sandra Souza

envelhecer, ao ponto do autor indicar três iniciativas a serem tomadas, em relação ao produto, para que a marca permaneça jovem: facelifting (rejuvenescimento estético), reinvenção e inovação (KAPFERER 2008: 450).

Essas observações convidam à verificação da realidade de mercado: será que alguma marca forte e valiosa atualmente ousa utilizar como elemento simbólico de seu logotipo a figura de um idoso, podendo, assim, ser associada ao conceito de velho/ultrapassado/fora do seu tempo? Para tanto, foi realizado um levantamento nos rankings de avaliação de marca mais conhecidos internacionalmente: os rankings BrandZ, da empresa de pesquisa de mercado Millward Brown ${ }^{6}$ e rankings da consultoria de branding Interbrand ${ }^{7}$. Foram considerados os rankings de espectro global e os focados em marcas brasileiras, todos referentes ao ano de 2012. Neste recorte, apenas uma marca foi selecionada, a única encontrada a utilizar um idoso como elemento simbólico: KFC (Kentucky Fried Chicken).

Com o intuito de pesquisar marcas popularmente conhecidas, mas não presentes em rankings de marcas mais valiosas financeiramente, foi analisado também o conteúdo do blog Mundo das Marcas $^{8}$, atualmente com 1569 cases de marcas brasileiras e internacionais. O resultado foi surpreendente, uma vez que, mesmo neste amplo universo de marcas consultadas, apenas outras três puderam ser incluídas: Quaker, Casa do Pão de Queijo e Uncle Bens.

\subsection{KFC (Kentucky Fried Chicken $)^{9}$}

A primeira marca a ser analisada é a KFC, $64^{\mathrm{a}}$ colocada no ranking global da Interbrand (2012) e $91^{\mathrm{a}}$ no ranking global da BrandZ (2012). A atual segunda maior rede de restaurante do mundo (só perde para o McDonald's) foi fundada em 1930, por Harland Sanders, como um simples restaurante de beira de estrada (Sanders Court \& Café). A KFC

\footnotetext{
${ }^{6}$ BrandZ é a marca dos rankings elaborados pela Millward Brown, empresa de pesquisa de mercado. Rankings disponíveis em: < http://www.millwardbrown.com/BrandZ/default.aspx> Acesso em: 5 nov.2012.

${ }^{7}$ INTERBRAND é uma empresa dedicada à pesquisa de branding que edita, anualmente, relatórios sobre as marcas mais valiosas do mundo e de determinadas regiões/países. Rankings disponíveis em: <http://www.interbrand.com/en/best-global-brands/2012/Best-Global-Brands-2012.aspx > Acesso em: 5 nov.2012.

${ }^{8}$ DIAS, Kadu. Mundo das Marcas. Blog especializado em marcas, marketing e publicidade. Disponível em: < http://mundodasmarcas.blogspot.com.br/>. Acesso em: 5 nov.2012.

${ }^{9}$ Os dados históricos da empresa foram obtidos por meio do site oficial da empresa: Colonel Sanders -. Disponível em: < http://colonelsanders.com/history.asp > Acesso em: 20/mar/2013.
} 
Efeito Benjamin Button: a figura do idoso na representação da identidade de marcas contemporâneas.

de Flavia Igliori Gonsales e Sandra Souza

tem por elemento simbólico, desde a primeira versão, o desenho do seu fundador, com seu sorriso simpático, cabelos brancos, óculos e gravatinha borboleta.

Em 1991, o logotipo ganhou as cores da bandeira americana (Figura 2c) e o componente simbólico, Coronel Sanders, recebeu um contorno azul. A versão de 1997 (Figura 2d) tem um tratamento visual mais detalhado: o azul tornou-se mais escuro, reservado para áreas em sombra, enquanto o bege (cor-de-pele), foi aplicado no rosto e no paletó. Além disso, fornecendo um pouco de dinamismo ao desenho, a figura do Coronel foi inclinada para a esquerda.

Fig. 2a - Logotipo e símbolo de 1952 a 1978

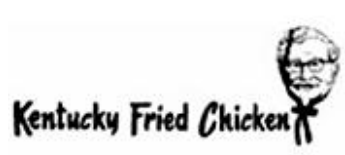

Fig. 2b - Logotipo e símbolo de 1978 a 1991

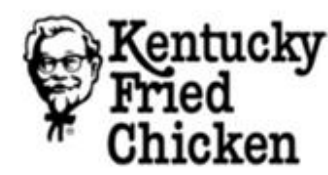

Fig. 2c - Logotipo e símbolo de 1991 a 1997

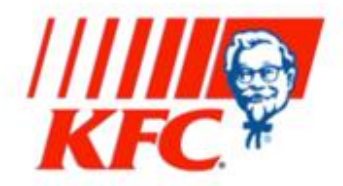

Fig. 2d - Logotipo e símbolo de 1997 a 2006

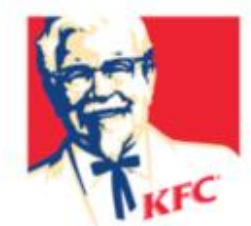

Fig. 2e - Logotipo e símbolo atuais, desde 2006 Fonte - Mundo das Marcas.

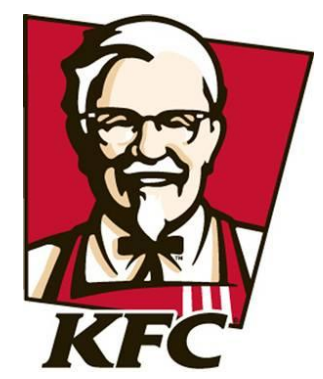

Na versão atual do logotipo (Figura 2e), redesenhado em 2006 pela agência Tesser, o azul dá lugar ao preto, alteração que aumentou o contraste visual ao mesmo tempo em que suavizou o aspecto nacionalista americano. $\mathrm{O}$ bege permaneceu em dois tons e o branco ficou restrito às áreas que, analogicamente, o são: cabelos, cavanhaque, roupa e as três listras do avental.

Na seção Portfolio de seu site ${ }^{10}$, a agência criadora do redesign explica o desafio do projeto, informando que uma pesquisa realizada anteriormente indicava o Coronel Sanders sendo reconhecido por $75 \%$ dos entrevistados como um vendedor de marca em vez de um cozinheiro inovador, trabalhador e de personalidade cativante. Ou seja, os atributos

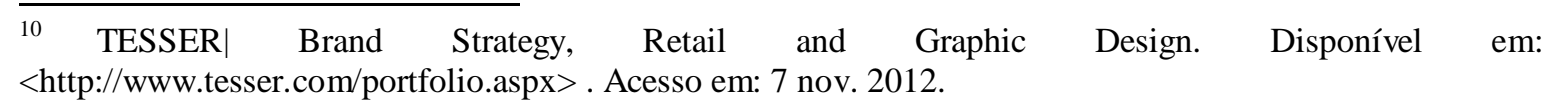


Efeito Benjamin Button: a figura do idoso na representação da identidade de marcas contemporâneas.

de Flavia Igliori Gonsales e Sandra Souza

originais, e ainda desejados pela empresa, não eram mais percebidos pelo público da marca. A fim de se reconectar com a nova geração de clientes, foi decidido que o redesign deveria manter os tradicionais elementos identificadores (óculos, cavanhaque e gravata borboleta), porém atualizando-se visualmente: fazer um Coronel mais jovem, energético e com um avental - para que as novas gerações, que não o conheceram, soubessem de sua postura pró-ativa, de quem inventava, cozinhava e servia as receitas.

Apesar de detalhar os desafios e as intenções do redesenho, a agência não apresenta, em seu site, qualquer menção a pesquisas realizadas posteriormente ao lançamento do logotipo/símbolo, a fim de mensurar o desempenho atingido, por meio da análise da percepção dos clientes.

\subsection{Quaker ${ }^{11}$}

A Quaker Oats (Aveia Quaker, em tradução literal) foi a primeira marca registrada de um cereal matinal, em 1877, cujo nome foi escolhido por "sugerir boa qualidade e honestidade", conforme haviam declarado os primeiros proprietários da empresa. Hoje, a marca pertence à PepsiCo Inc., que também possui as marcas Gatorade (isotônicos), Tropicana (sucos) e Frito-Lay (salgadinhos). Desde o início deste século, a marca passou a ser comunicada apenas pelo nome Quaker (sem o descritor aveia) já que a empresa produz, atualmente, vários outros produtos: cereais, snacks e cookies.

Originalmente, o elemento simbólico da Quaker Oats Company representava um homem de corpo inteiro, com trajes típicos de um quaker (Figura 3a), membro de uma comunidade religiosa inglesa fundada no século XVII e que se estabeleceu nos Estados Unidos por motivos de perseguição religiosa em seu país de origem. Assim, aparentemente, o símbolo original não fazia alusão direta à idade do personagem (não era obrigatoriamente um idoso, pois os quakers usavam peruca branca), mas buscava apropriar-se dos atributos de simplicidade, seriedade e hábitos saudáveis dos integrantes do grupo.

Com os anos, o logotipo foi sendo modernizado, e desde o primeiro redesenho, o elemento simbólico passou a representar o rosto de um senhor maduro, rechonchudo, saudável, sorridente, conhecido como Larry, um apelido carinhoso para o ícone da marca (Figuras 3b e 3c). Mesmo na versão mais estilizada e menos figurativa (Figura 3d), desenhada em 1972 por Saul Bass e utilizada por poucos anos, o senhor de cabelos brancos e chapéu grande pode ser

\footnotetext{
${ }^{11}$ Os dados históricos da marca Quaker foram obtidos por meio do site oficial WELCOME to Quaker Oats. Disponível em:< http://www.quakeroats.com/home.aspx> . Acesso em: 7 nov. 2012.
} 
Efeito Benjamin Button: a figura do idoso na representação da identidade de marcas contemporâneas.

de Flavia Igliori Gonsales e Sandra Souza

reconhecido. Pouco tempo depois, ainda na década de 1970, o símbolo voltou ao desenho original, com pequenas atualizações de cor e elementos gráficos de apoio (Figura 3e).

É possível inferir que a empresa não se sente à vontade com seu símbolo: desde 2010, ele foi alterado três vezes. As primeiras buscaram mais leveza com o fundo branco e aplicação de um azul mais claro e vivo para equilibrar a atratividade e energia do vermelho. Uma dessas recentes alterações (Figura 3h) rompeu o velho padrão de colocar o elemento simbólico dentro da forma oval, mas acabou prendendo-o novamente, dentro da letra $Q$ em caixa alta.

Fig. 3a - 1887

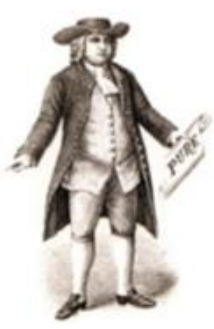

Fig. 3d - 1972, por Saul Bass

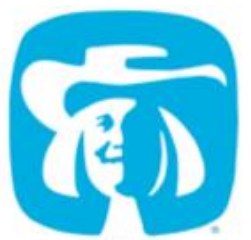

\section{QUAKER}

Fig. 3g - 2007

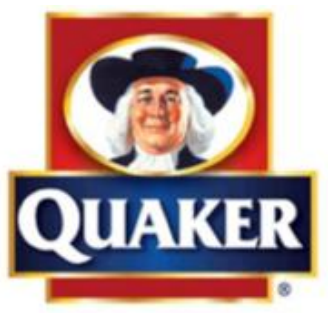

Fig. 3b - 1956,

por Jim Nash

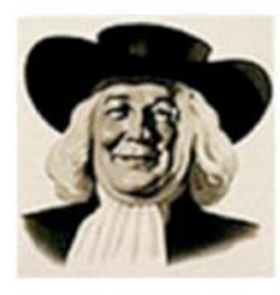

Fig. 3e - final dos anos 70

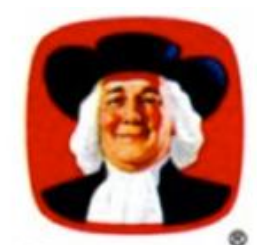

QUAKER

Fig. $3 \mathrm{~h}-2010$

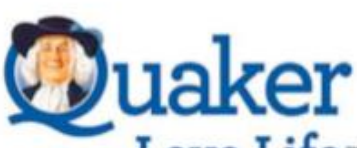

Love Life*
Fig. 3c-1957, por

Harold Sundblond

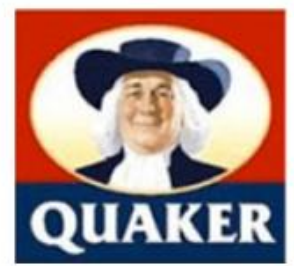

Fig.3f - criada em 1987

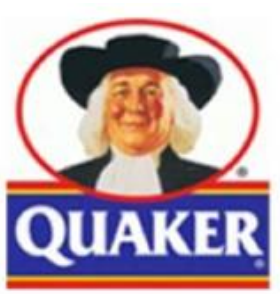

Fig. 3i - 2011

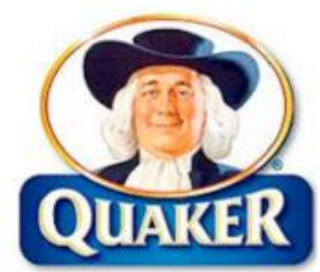


Efeito Benjamin Button: a figura do idoso na representação da identidade de marcas contemporâneas.

de Flavia Igliori Gonsales e Sandra Souza

Fig. 3j - 2012, atual

Fonte - Business Insider (Stampler 2012).

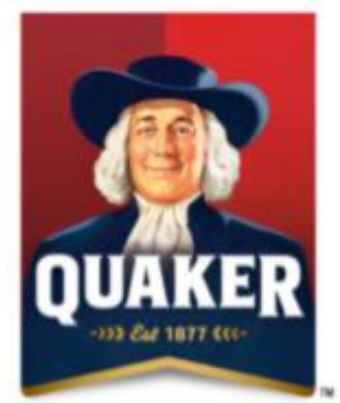

Sobre o atual símbolo (Figura 3j), a última reforma de Larry é parte da estratégia da PepsiCo Inc. em revigorar a Quaker globalmente, pois com 134 anos de existência, ela precisa manter uma imagem de marca atual e inovadora - segundo Justin Lambeth, Diretor de Marketing da marca (NASSAUER 2012). Representantes da empresa de design Hornall Anderson ${ }^{12}$, responsável pelo redesenho, explicam que o principal objetivo foi mudar o símbolo sutilmente, para que o consumidor não se incomodasse e para que não se perdesse a identificação da marca. Segundo eles, foram realizadas as seguintes alterações em Larry:

- Os cabelos foram cortados e os ombros apareceram, o que tornou Larry mais forte e vibrante, mais magro e com o pescoço mais longo;

- O queixo duplo foi retirado, assim como o rechonchudo do rosto, como se Larry perdesse uns 2,5 quilos (5 pounds);

- Foram mantidos os pés-de-galinha e um pouco de brilho em seus olhos, para que Larry não ficasse muito mais jovem (apenas “um pouco").

Ainda segundo a Hornall Anderson, para compensar o rejuvenescimento do personagem, alguns elementos gráficos foram repensados e adicionados no lay-out, para fortalecer a tradição e qualidade da marca:

- Um arremate em fita dourada, cujas pontas no lado inferior sugerem um selo de qualidade;

- Est 1877 grafado em dourado reforçou a mensagem de tradição e confiança, indicando o ano de fundação da marca.

Não foram reveladas pesquisas posteriores ao desenvolvimento do novo logotipo.

\footnotetext{
${ }^{12}$ Os dados do último redesenho do símbolo foram obtidos no site da agência, em A 134+ YEAR old icon brand gets a makeover - Hornall Anderson. Disponível em: <http://www.hornallanderson.com/casestudy/a134-year-old-iconic-brand-gets-a-makeover. Acesso em: 8 nov. 2012.
} 
Efeito Benjamin Button: a figura do idoso na representação da identidade de marcas contemporâneas.

de Flavia Igliori Gonsales e Sandra Souza

\subsection{Casa do Pão de Queijo ${ }^{13}$}

A Casa do Pão de Queijo foi fundada em 1967, pelo engenheiro Mário Carneiro, com uma loja no centro de São Paulo, e trouxe para os paulistanos o hábito do quitute mineiro, seguindo a receita de Dona Arthêmia, mãe do fundador. Segundo o site da empresa, o sucesso inicial fez a linha de produtos e o número de lojas se expandirem constantemente, que hoje formam a maior rede brasileira de franquias, com mais de 450 lojas e outros 400 pontos de venda em todo o país.

Segundo Dias (Mundo das Marcas 2012) as lojas foram padronizadas e uma nova identidade visual foi criada para desenvolver a franquia no final da década de 1980, quando Alberto Carneiro Neto (filho do fundador), passou a comandar a empresa e profissionalizou a gestão. Assim, o logotipo passou de um simples formato tipográfico e sem normatização (Figura 4a) para um identificador com forte elemento simbólico, a figura da Dona Arthêmia, criado pela agência Narita Design (Figura 4b): uma vovó de personalidade carinhosa, caseira e aconchegante - atributos aspiracionais da marca. A agência de assessoria de imprensa RP1 Comunicação, afirma que, em 2008, a Narita foi contratada para a atualização do logotipo (Figura 4c). Pode-se perceber que foram mantidas as cores verde e amarela (indicando a origem brasileira); as figuras da janela e da vovó foram liberadas do pesado retângulo de fundo; o componente tipográfico foi aumentado em tamanho para favorecer visibilidade e legibilidade, recursos que, ao final, forneceram um aspecto mais leve e moderno à identidade visual da marca.

Pode-se dizer que tanto a atualização como a modernização do projeto arquitetônico da franquia (também realizada na mesma época) objetivou marcar a fase de expansão e crescimento da rede geograficamente (no Brasil, em Portugal e Miami), enfrentar o aumento da concorrência (Starbucks no Brasil), e para se adaptar à tendência do mercado, o crescimento do segmento cafeterias de luxo.

\footnotetext{
${ }^{13}$ Os dados históricos da marca Casa do Pão de Queijo foram obtidos por meio do site oficial da empresa. Disponível em:<http://www.casadopaodequeijo.com.br/nossa_historia.php >. Acesso em: 20 mar. 2013.
} 
Efeito Benjamin Button: a figura do idoso na representação da identidade de marcas contemporâneas.

de Flavia Igliori Gonsales e Sandra Souza

Fig. 4a - 1967

Fig. 4b - 1987
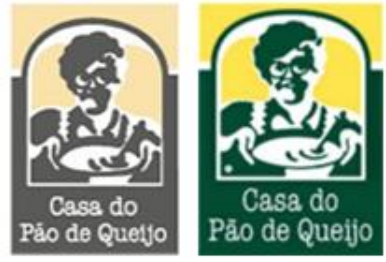

Fonte - Figuras 4a e 4c - Narita Design
Fig. 4c - atual, desde 2007

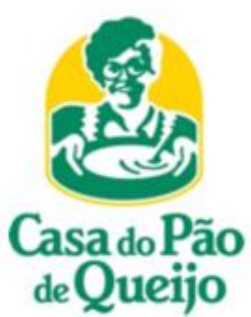

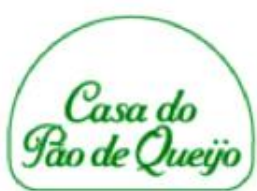

\subsection{Uncle Bens ${ }^{14}$}

Segundo o site oficial da marca, os primeiros gestores da então Converted Rice, Inc. (empresa antecessora da Uncle Ben's Inc.), no final dos anos 1940, tiveram a ideia de usar a figura lendária do Tio Ben, um fazendeiro texano afrodescendente conhecido na região pela excelência do arroz que produzia, para realizar uma estratégia de marketing que estabelecesse associação com o atributo de alta qualidade e que conquistasse clientes novos. Foi assim criada a marca Uncle Ben's Converted Brand Rice, em 1947. Hoje, sabe-se que a imagem do rosto pertencia a um maitre de restaurante em Chicago, que posou para o retrato, uma vez que o real Tio Ben já havia falecido - o que justifica o paletó e a gravata borboleta do personagem, originalmente partes do uniforme de trabalho (Figura 5a).

Ao longo de mais de 60 anos de existência, o logotipo da Uncle Ben's passou por diversas atualizações: inicialmente apenas tipográfico, com o Tio Ben aplicado como grande ilustração da embalagem, posteriormente sem nenhuma referência ao personagem, como se pode ver nas embalagens das décadas de 1960 a 1970 (Figura 5b), e voltando a utilizar o Tio Ben como elemento simbólico inserido em um círculo, na década de 1980 (Figura 5c).

Pode-se dizer que há 30 anos o símbolo da Uncle Ben's tem passado por poucas alterações. O único redesenho encontrado por este estudo ocorreu em 2007, quando a empresa realizou uma campanha a fim de acabar com as acusações de racismo pelas quais passava: associações não governamentais alegaram que a empresa tratava o personagem como um serviçal, sem conferir a ele um sobrenome e utilizando a designação uncle (usada antigamente por americanos brancos sulistas, que se recusavam a chamar homens da raça negra de senhor). A estratégia, segundo o jornal The New York Times (Elliot 2007), passou a comunicar Ben como o presidente da empresa fictícia Uncle Ben's (a marca pertence à empresa americana Mars Inc.). A propaganda impressa e o site exibiram um opulento escritório e uma agenda lotada de

\footnotetext{
${ }^{14}$ Os dados históricos da marca Uncle Ben's foram obtidos por meio do site oficial da marca. Disponível em:< http://www.unclebens.com/Common/AboutUS> . Acesso em: 20 mar. 2013.
} 
Efeito Benjamin Button: a figura do idoso na representação da identidade de marcas contemporâneas.

de Flavia Igliori Gonsales e Sandra Souza

compromissos e viagens importantes, e marcaram a passagem da assinatura gráfica tradicional

(Figura 5d) para o atual logotipo e elemento simbólico vigentes. (Figura 5e).

Fig. 5a - final dos anos 1940

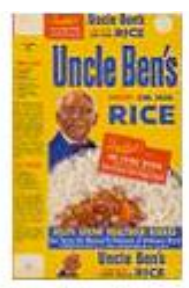

Fig. 5b - décadas de 1960-70

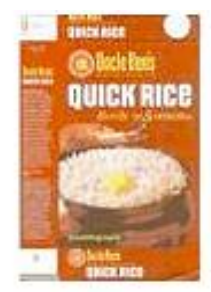

Fig. 5c - década de 1980

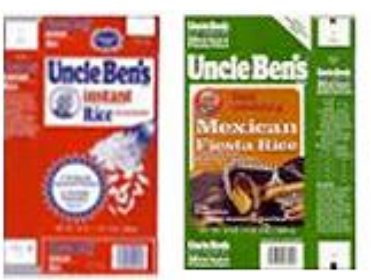

Fig. 5d-até 2007

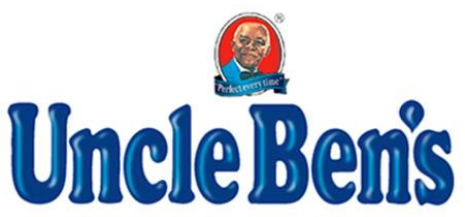

Fig. 5e - logotipo atual, desde 2007

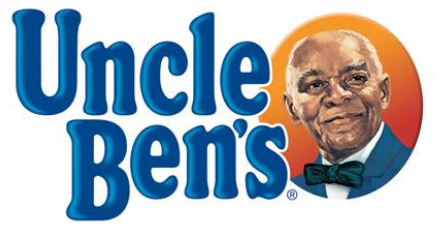

Fontes - Figuras 5 a a $5 \mathrm{c}$ - site oficial da marca.

Figuras 5d e 5e - Mundo das Marcas

Nesse recente redesenho não ocorreu um rejuvenescimento perceptível em Ben, mas é possível dizer que a figura recebeu um tratamento especial, um visual mais distinto: o tamanho do símbolo foi aumentado em relação ao logotipo, o paletó tornou-se azul marinho, mais sóbrio e elegante (substituindo o forte azul celeste), a gravata borboleta apareceu por inteiro, o brilho e a cor da pele (mais marrom, menos laranja) tornaram-se mais contrastantes.

\section{CONSIDERAÇÕES FINAIS}

Conforme visto, atualmente são poucas as marcas que se expressam visualmente com elementos simbólicos que representem a figura de um(a) idoso(a). As únicas quatro marcas levantadas que o fazem (Quadro 1), mostram, em maior ou menos grau, certa dificuldade em transmitirem uma imagem de marca atual, dinâmica, jovem, ao mesmo tempo em que são representadas visualmente pela figura de um velhinho. 
Efeito Benjamin Button: a figura do idoso na representação da identidade de marcas contemporâneas.

de Flavia Igliori Gonsales e Sandra Souza

Quadro 1 - síntese comparativa entre as marcas analisadas

Fonte - desenvolvido pelos autores

\begin{tabular}{|c|c|c|c|c|}
\hline & KFC & QUAKER & $\begin{array}{l}\text { CASA DO PÃO } \\
\text { DE QUEIJO }\end{array}$ & UNCLE BENS \\
\hline $\begin{array}{l}\text { Logotipo e } \\
\text { símbolo }\end{array}$ & 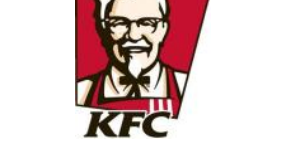 & QUAK & $\begin{array}{c}\text { CasadoPão } \\
\text { deQueijo }\end{array}$ & \\
\hline $\begin{array}{l}\text { Segmento } \\
\text { de atuação } \\
\text { da marca }\end{array}$ & $\begin{array}{l}\text { Alimentação } \\
\text { (rede de franquia } \\
\text { de fast food) }\end{array}$ & $\begin{array}{c}\text { Alimentação } \\
\text { (alimentação saudável) }\end{array}$ & $\begin{array}{l}\text { Alimentação } \\
\text { (rede de franquia } \\
\text { de snacks) }\end{array}$ & $\begin{array}{l}\text { Alimentação } \\
\text { (arroz) }\end{array}$ \\
\hline $\begin{array}{l}\text { Origem/ } \\
\text { atuação }\end{array}$ & $\begin{array}{l}\text { Marca americana, } \\
\text { presença global }\end{array}$ & $\begin{array}{l}\text { Marca americana, } \\
\text { presença global }\end{array}$ & $\begin{array}{l}\text { Marca brasileira, em } \\
\text { expansão internacional }\end{array}$ & $\begin{array}{l}\text { Marca americana, } \\
\text { presença global }\end{array}$ \\
\hline $\begin{array}{l}\text { Elemento } \\
\text { simbólico }\end{array}$ & $\begin{array}{l}\text { Coronel Sanders, o } \\
\text { fundador }\end{array}$ & $\begin{array}{l}\text { Larry, figura típica } \\
\text { de um quaker }\end{array}$ & $\begin{array}{l}\text { A vovó Arthêmia, } \\
\text { mãe do fundador }\end{array}$ & $\begin{array}{c}\text { Tio Ben, fazendeiro } \\
\text { texano } \\
\text { afrodescendente }\end{array}$ \\
\hline $\begin{array}{l}\text { Objetos } \\
\text { acessórios }\end{array}$ & $\begin{array}{c}\text { Óculos } \\
\text { Avental } \\
\text { Gravata borboleta } \\
\text { - }\end{array}$ & $\begin{array}{c}- \\
- \\
\text { Lenço/gravata } \\
\text { Chapéu }\end{array}$ & $\begin{array}{c}\text { Óculos } \\
\text { Avental } \\
\text { - } \\
\text { Tigela e colher }\end{array}$ & $\begin{array}{c}- \\
\text { Gravata borboleta } \\
\text { Paletó }\end{array}$ \\
\hline $\begin{array}{l}\text { Aparência } \\
\text { física }\end{array}$ & $\begin{array}{l}\text { Cabelos brancos } \\
\text { Cavanhaque branco } \\
\text { Marcas de idade }\end{array}$ & $\begin{array}{c}\text { Cabelos brancos } \\
\text { - } \\
\text { Marcas de idade }\end{array}$ & $\begin{array}{c}\text { Cabelos brancos } \\
\text { - } \\
\text { Marcas de idade }\end{array}$ & $\begin{array}{l}\text { Cabelos brancos } \\
\text { Careca } \\
\text { Marcas de idade }\end{array}$ \\
\hline $\begin{array}{l}\text { Personali- } \\
\text { dade }\end{array}$ & Feliz, risonho & Feliz, risonho & Feliz, risonho & Feliz, risonho \\
\hline Ação & Contemplando & Contemplando & Trabalhando & Contemplando \\
\hline $\begin{array}{l}\text { Última } \\
\text { alteração no } \\
\text { símbolo }\end{array}$ & $\begin{array}{l}\text { 2006, levemente } \\
\text { remoçando o Coronel }\end{array}$ & $\begin{array}{l}\text { 2012, fortemente } \\
\text { remoçando Larry }\end{array}$ & $\begin{array}{l}\text { 2008, sem remoçar } \\
\text { vovó Arthêmia }\end{array}$ & $\begin{array}{c}\text { 2007, sem remoçar } \\
\text { tio Ben }\end{array}$ \\
\hline
\end{tabular}

O maior exemplo de busca por uma atualização/modernização foi encontrado na marca Quaker. Pode-se observar as constantes alterações em seu logotipo e símbolo nos últimos dois anos, demonstrando o conflito entre o elemento simbólico (a figura do idoso) e a demanda mercadológica contemporânea por marcas associadas aos conceitos de juventude, energia e saúde, conforme verificado no levantamento teórico desta pesquisa. Como resultado, o Larry passou por um programa estético completo (facelifting), envolvendo cabelo, pele, peso, e ao final, rejuvenescendo na medida exata para não perdesse o poder de identificar a marca junto a seus consumidores antigos.

A marca KFC também demonstrou a necessidade de se rejuvenescer, conforme visto no design do último logotipo e nas declarações da agência criativa responsável pelo projeto. Mais uma vez, o desafio foi dar a impressão de energia e jovialidade, mas ao mesmo tempo, manter o tradicional velhinho, ícone da marca. 
Efeito Benjamin Button: a figura do idoso na representação da identidade de marcas contemporâneas.

de Flavia Igliori Gonsales e Sandra Souza

Das quatro marcas analisadas, duas não remoçaram a figura idosa do elemento simbólico: Casa do Pão de Queijo e Uncle Bens. Na primeira, as alterações no traço foram mais no intuito de aumentar a legibilidade e dar leveza ao conjunto logotipo e símbolo, do que propriamente a fim de diminuir a idade da vovó. De qualquer modo, a necessidade de manter a marca atual e moderna provocou um redesenho, comprovando a importância dos elementos de identidade visual como manifestações dos valores marcários.

Na marca Uncle Ben's, o redesenho foi provocado por um problema urgente: a questão racial. Os sinais de idade de Ben não foram alterados. Faz-se então a pergunta: resolvidos os problemas de acusação da marca por ser racista, será que seu elemento simbólico será remoçado em breve?

Não por coincidência, as quatro marcas analisadas são do segmento de alimentação, onde a figura de um avô ou avó (ou um tio idoso), transmitindo a ideia de carinho, cuidado, nutrição, atenção, pode coexistir às estratégias de renovação, inovação e lançamentos da marca - que o atual mercado de alta competitividade exige. Mesmo assim, a coexistência não é tranquila: a Quaker, marca com forte associação ao conceito de saudabilidade, esmaeceu os sinais de idade e emagreceu seu símbolo, Larry.

Na questão da idade representada por meio dos elementos simbólicos da identidade visual da marca, não houve grande diferença em relação ao gênero. Tanto as figuras masculinas, como a feminina, estão com cabelos brancos e, sorridentes, se manifestam bem humorados e simpáticos. O Coronel e Arthêmia usam óculos. A única diferenciação pode ser observada em relação à postura/ação: enquanto os homens estão contemplativos ou para serem contemplados, a mulher está literalmente com a mão na massa, segurando uma tigela de massa de pão de queijo e oferecendo-a ao observador. Seria algum sinal de papéis sociais/sexuais tradicionais ou mera coincidência?

Como demonstrado, os elementos visuais de identidade marcária não são meros recursos táticos, mas sim questão estratégica na construção de marcas fortes e valiosas objetivo final de todo o programa de branding - na medida em que, além de promoverem a identificação da marca, favorecem sua associação a valores desejáveis, aspiracionais. Esse estreito vínculo marca-logotipo (incluído o elemento simbólico) explicaria, segundo Kapferer (2008) a necessidade das empresas em redesenhar seu sistema de identidade visual quando passam por transformações significativas na gestão de sua(s) marca(s). O contrário também ocorre: quando estão a fim de obter energia e inspiração, primeiramente redesenham seu símbolo para, então, efetivarem as mudanças já visualmente representadas. 
Efeito Benjamin Button: a figura do idoso na representação da identidade de marcas contemporâneas.

de Flavia Igliori Gonsales e Sandra Souza

Estas reflexões a propósito das marcas analisadas podem remeter à história de Benjamin Button (BB), mencionada na introdução, pela qual um bebê que nasce com um corpo idoso e mente madura vai remoçando sua aparência e espírito com o passar do tempo, em uma experiência inversa à maioria dos mortais. Aplicado ao branding, o efeito $\mathrm{BB}$ representa a estratégia mercadológica de rejuvenescimento do patrimônio simbólico de marca por meio do redesenho de seus elementos identificadores, entre outros programas. $\mathrm{O}$ facelifting, às vezes sutil, às vezes mais enfático, é realizado no intuito de viabilizar e/ou renovar a realização de histórias de amor entre as marcas e seus consumidores, antigos e novos. Os gestores, cientes disso, se dedicam cada vez mais no desenvolvimento de manifestações visuais em alinhamento com os valores marcários fundamentais, capazes de criar uma conexão emocional-afetiva mais intensa com seus públicos.

Conforme visto, a associação estratégica entre formas visuais e conceitos aspiracionais para a criação de marcas relevantes e perenes ainda representa um desafio possível de ser enfrentado apenas com uma aproximação essencialmente multidisciplinar que integre aspectos técnicos, simbólicos, comportamentais e econômicos por meio de metodologias e conhecimentos advindos do marketing, da comunicação e do design.

\section{REFERÊNCIAS BIBLIOGRÁFICAS}

AAKER, D. Marcas: brand equity, gerenciando o valor da marca. São Paulo: Elsevier, 1998.

AAKER, D., JOACHIMSTHALER, E. Como construir marcas líderes. Porto Alegre: Bookman, 2007.

ALLEN, T., SIMMONS, J. "Visual and verbal identity". In: CLIFTON, R., SIMMONS,J. (eds). Brands and Branding (The Economist Series). London: Bloomberg Press, 2004: 113-126.

BAUMAN, Z. Modernidade líquida. Rio de Janeiro: Zahar, 2001.

BRAND Experience Design Agency - Hornall Anderson. Disponível em: <http://www.hornallanderson.com/ > Acesso em: nov. 2012.

CASA DO PÃO DE QUEIJO. Site oficial. Disponível em < http://www.casadopaodequeijo.com.br/nossa_historia.php>. Acesso em: 10 nov. 2012.

CHAVES, N. Pensamento tipológico. (tradução de Alvaro Sousa). In: Reflexão+Debate= FOROALFA. Disponível em: <http://foroalfa.org/articulos/pensamentotipologico>. Acesso em: fev. 2013.

COSTA, J. A imagem da marca: um fenômeno social. São Paulo: Rosari, 2011. 
Efeito Benjamin Button: a figura do idoso na representação da identidade de marcas contemporâneas.

de Flavia Igliori Gonsales e Sandra Souza

DIAS, K Mundo Das

Das Marcas. Disponível

http://mundodasmarcas.blogspot.com.br/2006/09/

casa-do-po-de-queijo-mania-nacional.html>. Acesso em: 10 nov. 2012.

ELliOTT, S. "Uncle Ben, Board Chairman". In: The New York Times, 30/03/2007. Disponível em http://www.nytimes.com/2007/03/30/business/media/30adco.html?pagewanted=all\&_ $=2 \&>$. Acesso em: 20 mar. 2013.

GOBÉ, Marc. BrandJam. Rio de Janeiro: Rocco, 2010.

GOBÉ, Marc. Emocional branding. New York: Allworth Press, 2009.

HALL, S. A identidade cultural na pós-modernidade. Rio de Janeiro: DP\&A Editora, 2000.

HARVEY, D. Condição Pós-Moderna: uma pesquisa sobre as origens da mudança cultural. São Paulo: Edições Loyola, 1992.

IBGE. Em 2011, a esperança de vida ao nascer era de 74,08 anos. Comunicação Social. Sala de Imprensa. 29 de nov.de 2012. Disponível em: $<$ http://www.ibge.gov.br/home/presidencia/noticias/noticia_visualiza.php?id_notici a=2271\&id_pagina=1> Acesso em: 11 de março de 2013.

INTERBRAND Creating and Managing Brand Value. Best Global Brands. Disponível em: < http://www.interbrand.com/en/best-global-brands/2012/Best-Global-Brands-2012.aspx > Acesso em: nov.2012

KAPFERER, JN. New Strategic Brand Management: Creating and Sustaining Brand Equity Long Term. $4^{\text {a }}$ ed. London: Kogan Page, 2008.

LENCASTRE, P., CORTE-REAL, A. One, two, three: a practical brand anatomy. Journal of Brand Management, 17, 399-412 (abril/maio 2010).

LINDSTROM, M. Brand sense: build powerful brands though touch, taste, smell, sight, and sound. New York: Free Press, 2005.

LINDSTROM, M. Buyology: Truth and lies about what we buy. New York: Radom House, 2008.

LIPOVETSKY, G., ROUX, E. O luxo eterno: da idade do sagrado ao templo das marcas. São Paulo: Companhia das Letras, 2005.

LIPOVETSKY, G., SEBASTIER, C. Os tempos hipermodernos. São Paulo: Barcarolla, 2004.

MILETSKY, J., SMITH, G. Perspectives on Branding. USA: Course Technology PTR, 2009. 
Efeito Benjamin Button: a figura do idoso na representação da identidade de marcas contemporâneas.

de Flavia Igliori Gonsales e Sandra Souza 69

MILLWARD BROWN. Rankings BrandZ. Disponíveis em:

<http://www.millwardbrown.com/BrandZ/default.aspx > Acesso em: 10 nov. 2012.

NARITA DESIGN. Site oficial. Disponível em: < http://www.naritadesign.com.br/html/ portifolio_det.php?24_3>.Acesso em: 10 nov. 2012.

NASSAUER, S. "Larry, Quaker of Oatmeal Fame, Gets a Makeover". In: Wall Street Journal, 29/03/2012. Disponível em http://online.wsj.com/article/SB10001424052702303404704577309540451674640.ht ml> . Acesso em: 10 nov. 2012.

OMS. "Novo envelhecimento". In: Agência FAPESP, 01/04/2011. Disponível em < http://www.agencia.fapesp.br/13669>. Acesso em: 10 nov. 2012.

RP1 COMUNICAÇÃO. "Casa do Pão de Queijo apresenta nova identidade visual na ABF Franchising 2008”. Dxpo Disponível em: < http://www.rp1.com.br/redator/item23610.shtml> Acesso em: 10 nov. 2012.

SCHMITT, B.; SIMONSON, A. A Estética do Marketing: como criar e administrar sua marca, imagem e identidade. São Paulo: Nobel, 2002.

SEMPRINI, A. A marca pós-moderna. São Paulo: Estação das Letras e Cores, 2010.

STAMPLER, L. "Watch The Evolution Of The Quaker Man". In: BUSINESS Insider, 10/02/2012. Disponível em < http://www.businessinsider.com/heres-the-evolution-ofthe-quaker-man-2012-2?op=1>. Acesso em 15 dez. 2012

TASTE Why Fresh is Better|KFC.com. Disponível em: < http://www.kfc.com/> Acesso em: 5 nov. 2012 .

TESSER| Brand Strategy, Retail and Graphic Design. Disponível em: <http://www.tesser.com/portfolio.aspx> . Acesso em: 7 nov. 2012.

UNCLE BENS - Instant \& Long Grain Rice Recipes. Disponível em: < http://www.unclebens.com/Common/AboutUS>. Acesso em: 20 mar. 2013.

WELCOME to Quaker Oats. Disponível em:< http://www.quakeroats.com/home.aspx > . Acesso em: 7 nov. 2012.

Artigo submetido: 05/04/2013

Artigo aprovado: 20/09/2013 